\title{
DEL TRANSFORMISMO TEATRAL \\ A LA PERFORMATIVIDAD TRANSGÉNERO COTIDIANA. FRAGMENTOS DE UNAS MEMORIAS TRANS
}

\section{PRESENTACIÓN*}

\author{
Juan Martínez Gil \\ Universitat Jaume Jaume I de Castelló \\ gilju@uji.es \\ Rafael M. Mérida Jiménez \\ Universitat de Lleida \\ rafaelmanuel.merida@udl.cat
}

El campo de los estudios sobre autobiografías y memorias de la diversidad sexual y de género en las culturas hispánicas ha venido creciendo durante los últimos años en los ámbitos investigadores español y americanos ${ }^{1}$. La diversidad de las fuentes primarias es enorme, al igual que sus emplazamientos; en ocasiones, los documentos que rescatan esta diversidad se encuentran casi ocultos en lugares inesperados. Tan inesperados como una bitácora digital con los análisis académicos de un docente universitario. Así, el texto que aquí presentamos es solo una muestra parcial de las memorias de Luis Felipe Díaz, durante más de tres décadas catedrático de Estudios Hispánicos en la Universidad de Puerto Rico-Río Piedras. Pero también son las memorias de la artista Lizza Fernanda, quien, desde aproximadamente 1976, ha realizado shows en más de 40 clubs y cabarets en los Estados Unidos de América y Puerto Rico. Como muestran estas páginas, desde hace más de una década vive como Lizza en ambos universos, el académico y el artístico. La identidad de Lizza Fernanda, que en un principio representaba una actividad próxima a las female impersonators o drag queens, hoy en día se mueve en la órbita transgenérica.

Luis Felipe Díaz nació en Aguas Buenas (Puerto Rico) en 1950. En 1965 emigró con su familia a Chicago, donde estudió en la escuela secundaria, y se trasladó a Puerto Rico para realizar sus estudios universitarios en 1969. Regresó a Chicago en 1975 para estudiar una maestría en Spanish, Italian and Portuguese en la University of Illinois. Fue en esta época en la que, paralelamente a su carrera académica, nació Lizza Fernanda, periodo que describen estas memorias. Tras defender su tesis doctoral en la University of Minnesota en 1984 -que acabaría publicándose con el título Ironía e ideología en La Regenta de Leopoldo Alas Clarín (1992)-, Luis Felipe Díaz regresó a Puerto Rico, donde comenzó su actividad como profesor e investigador universitario, primero en la Universidad Interamericana, más tarde en el recinto de Río Piedras de la Universidad de Puerto Rico y, tras su jubilación, en

DOI: https://doi.org/10.25145/j.clepsydra.2021.21.12

Revista Clepsydra, 21; marzo 2021, pp. 269-293; ISSN: e-2530-8424 
el Hostos Community College de Nueva York. También ha realizado estancias de investigación en The City University of New York. Entre sus méritos académicos destacan la publicación de numerosos artículos y volúmenes, el dictado de clases y conferencias o la dirección de tesis de maestría y doctorado. Si atendemos a sus libros publicados, encontramos monografías como Semiótica, psicoanálisis y postmodernidad (1999), Modernidad, postmodernidad y tecnocultura actual (2011) o la coedición de Globalización, nación, postmodernidad: estudios culturales puertorriqueños (2001). También destacan sus estudios La na(rra) ción en la literatura puertorriqueña (2008) y De charcas, espejos, velorios e infantes en la literatura puertorriqueña (2011), así como su más reciente Eros y violencia en la literatura hispanoamericana del siglo XX (2015).

De forma paralela al desarrollo de su trabajo académico, creció su actividad artística como Lizza Fernanda, que se presentaba en un principio como una doble identidad que oscilaba entre lo travesti y lo trans ${ }^{2}$. Lizza ha interpretado sus performances en muy diversas ciudades, empezando por aquellas en donde ha vivido (Chicago, San Juan de Puerto Rico, Nueva York o Miami) y ha realizado shows con estrellas drag de la talla de Miss Ketty o Mirkala Crystal. Su figura ha suscitado el interés de los principales medios de comunicación puertorriqueños e hispanoamericanos, impresos y audiovisuales. También en el mundo universitario, su figura ha despertado la atención de diversxs investigadorxs (Perales; La Fountain-Stokes Lizza).

A raíz de tan atractiva trayectoria se filmó un documental centrado en su persona, Luis/Lizza (2015), realizado por Joelle González-Laguer, que explora ambas facetas vitales. La cinta fue presentada en numerosos centros académicos (Yale University, The City University of New York, Universidad de Puerto Rico) y fue seleccionada en diferentes festivales internacionales (Puerto Rico QueerFest o Havana Film Festival New York), muestra del interés y acogida que su figura ha suscitado en el circuito cultural. Este documental, de 14 minutos de duración, se divide en dos partes narrativamente muy distinguibles: en la primera se muestra una clase del profesor Luis Felipe -completamente ataviado como Lizza, claro está- y la dinámica pedagógica con su alumnado; en la segunda observamos una entrevista de tono más confesional, donde Lizza, de cara a la cámara, se sincera con el espectador en torno a diferentes cuestiones relativas a su identidad.

* Esta presentación forma parte del proyecto de investigación «Memorias de las masculinidades disidentes en España e Hispanoamérica» (PID2019-106083GB-I00) del Ministerio de Ciencia e Innovación del Gobierno de España.

${ }^{1}$ Volúmenes como La Fountain-Stokes Queer...; Peralta y Mérida Jiménez; Berzosa; Platero, Suárez y Trujillo; Peralta; Mérida Jiménez; Berzosa y Trujillo e incluso el presente monográfico muestran este reciente interés por echar la vista atrás y rebuscar en el archivo. Buena prueba también serían los proyectos de investigación que están trabajando este ámbito: así, por citar solo dos casos, «CRUSEV-Cruising the 1970s: Pre-HIV/AIDS Queer Sexual Cultures», del programa Horizon 2020 de la Unión Europea, o «Memorias de las masculinidades disidentes en España e Hispanoamérica», del Gobierno de España, en el que se inscribe la presente edición.

${ }^{2}$ En el trabajo de Perales, Lizza confiesa que toma su nombre de la artista Liza Minne1li. Su segundo nombre, Fernanda, puede venir de la transformación del «Felipe» original, a la vez que podría ser un guiño a la conocida zarzuela Luisa Fernanda (1932), de Federico Moreno Torroba. 
«Del transformismo teatral a la performatividad transgénero cotidiana. Fragmentos de unas memorias trans» es un recuento autobiográfico sobre su etapa de formación trans en la Chicago de los años 70. Los editores hemos partido de su blog universitario Postmodernidad puertorriqueña ${ }^{3}$. En el proceso de edición, Lizza Fernanda ha tenido la amabilidad y la generosidad de revisar la selección y de ampliar los textos originales. Esta es una muestra representativa no solo de una trayectoria insólita en el mundo hispánico (profesor e investigador universitario, de drag queen a transgénero), sino también de las voces perdidas de tantos sujetos que, por su posición social o situación personal, nunca han podido superar la subalternidad a la que la heteronormatividad los condenaba y aún condena. Esta aportación de Lizza Fernanda / Luis Felipe supone un valioso rescate testimonial tanto para los estudios de la diáspora hispana, al recuperar el contexto de las personas migrantes en la Chicago de los años 60 y $70^{4}$, como para los estudios centrados en el análisis de la memoria LGBT+ en los Estados Unidos de América y Puerto Rico.

Desde esta perspectiva, «Del transformismo teatral...» se ubicaría en el archivo de documentos autobiográficos trans puertorriqueños, como es el caso de las memorias de Soraya, Hecha a mano: disforia de género (2014), una de las protagonistas del documental Mala Mala (2014), dirigido por Antonio Santini y Dan Sickles ${ }^{5}$. A su vez, tendría cabida en la literatura autobiográfica boricua de la diáspora LGBT+, ilustrada en figuras señeras como Manuel Ramos Otero o Luz María Umpierre. De esta manera, las vivencias de Luis Felipe / Lizza Fernanda en la ciudad de Chicago complementarían las de Ramos Otero en el Nueva York de los años 60 y 70, pues ambas urbes acogieron una gran comunidad hispana migrante. En el trabajo de La Fountain-Stokes Queer... encontramos un generoso análisis de estas culturas de la diversidad sexual en la diáspora puertorriqueña. Del mismo modo, el texto de Lizza Fernanda recrea diferentes vivencias relacionadas con el transformismo en Estados Unidos durante aquellas décadas que complementarían los análisis de Esther Newton en su clásico Mother Camp (1972).

${ }^{3}$ La edición del presente texto nace de dos entradas del blog Postmodernidad puertorriqueña (http://postmodernidadpuertorriquena.blogspot.com/2012/04/datos-de-luis-felipe-y-lizza-fernanada. html y http://postmodernidadpuertorriquena.blogspot.com/2012/05/blog-post.html). Tras interrelacionarlas y disponer de un recuento unificado, han sido revisadas y ampliadas por la autora. A lo largo de los originales que confluyen se constatan varias fechas de escritura. De esta manera, no se establece un único presente de la enunciación, sino varios (2009, 2011, 2012, 2017), que corresponden a diferentes estadios y tiempos de redacción. El año 2020 es el de la revisión que aquí se publica. Los editores deseamos agradecer a Lawrence La Fountain-Stokes su inestimable ayuda al inicio de nuestra labor. Y, por supuesto, a Lizza Fernanda / Luis Felipe Díaz, su entrańable cariño y generosidad. Se ha respetado el uso de todos aquellos registros lingüísticos y marcas de estilo que ha deseado mantener la autora. Aprovechamos para recomendar este blog, que ha recibido más de 230000 visitas. Destinado a profesorado y alumnado universitario, contiene análisis de obras literarias hispánicas desde perspectivas teóricas tan diversas como el psicoanálisis, el posestructuralismo, los estudios poscoloniales y queer.

${ }^{4}$ Para una información más extensa del contexto migratorio puertorriqueño en la ciudad de Chicago, véase la monografía de Ramos-Zayas.

${ }_{5}$ Véase La Fountain-Stokes, Mala. 
La voz de Lizza Fernanda rescata un contexto en el que las escasas posibilidades de realización personal y profesional alejaban a trans, drags, jotos, maricas y putos migrantes y racializados de una educación universitaria. A su vez, el texto recorre en primera persona diferentes cuestiones sobre la vida y experiencias trans que suelen ser centrales en este tipo de relatos, como los espacios de homotransocialización o las dificultades de integración social. El texto que presentamos permite repasar diferentes cuestiones de gran interés: en primer lugar, resulta llamativa la amplitud terminológica con la que Lizza Fernanda describe su realidad. Para ello utiliza indistintamente las formas «trasvestido»/«travestido», "transformista», «crossdresser» o "gay». En una ocasión se desmarca de la terminología «transexual» y «trans» afirmando que "yo no soy así». No obstante, en fragmentos de las publicaciones del blog no recogidos en esta selección, se reafirma como "trans»: "Las experiencias que ha tenido Lizza durante los últimos treinta y seis años me han servido para ser en parte de como soy ahora y como el prof. Luis Felipe Díaz ya en un trans» ${ }^{6}$. Este devenir de las formas lingüísticas identitarias sugiere una compleja búsqueda exterior y una rica reflexión interior que reflejan diferentes experiencias vitales y estadios de escritura. Por ello, nadie deberá extrañarse si encuentra intercambiados algunos de estos términos a lo largo del texto, pues fluctúan de manera irregular para denominar realidades trans de diversa índole.

Otra de las terminologías usadas por Luis Felipe / Lizza Fernanda, de gran relevancia en el contexto boricua, es la de «loca» («La energía esa la poseían las llamadas locas, así que yo sospechaba que era más como ellas y no como mis macharranes amigos»). Este término vendría a situar una dicotomía dentro del contexto gay puertorriqueño, donde encontramos unos individuos más femeninos («locas»o «bugarrones») y otros más masculinos («macharranes»). En cualquier caso, su relevancia vendría dada por la vindicación que supone la feminidad gay en un contexto hostil, patriarcal, donde la feminidad es connotada de forma negativa, especialmente si es aplicada a un varón, incluso dentro de la propia comunidad LGBT+. En relación con esta oscilación entre Lizza Fernanda y Luis Felipe, también resulta notorio el cambio en la narración de la tercera a la primera persona de forma intermitente a lo largo del texto. En algunos puntos de la narración se vuelve a esta tercera persona propia de la nota biográfica, aunque predomine el tono autobiográfico. Probablemente deba identificarse con el uso que frecuentemente utilizan las travestis para hablar de sí mismas de forma dislocada, especialmente en referencia a su nombre femenino, remarcando el carácter de "personaje» de su performance y desligándolo de su identidad masculina oficial, aunque, como en el caso de Luis Felipe / Lizza Fernanda, esta frontera acabe desdibujándose.

Otras cuestiones de gran interés son los pasajes en los que se narra la peligrosa relación de los inmigrantes hispanos con la policía migratoria. Aunque las políticas de deportación no afectaban a los puertorriqueños por la entidad de Estado

${ }^{6}$ http://postmodernidadpuertorriquena.blogspot.com/2012/04/datos-de-luis-felipe-y-lizza-fernanada.html. 
Libre Asociado de la isla, el texto muestra cómo afecta a otros latinos migrantes: «Muchas locas mejicanas fueron arrestadas y llevadas por los policías de la migra a lugares muy lejanos (en la frontera) y nunca más las volvimos a ver». A las necesidades económicas que motivan a los sujetos migrantes, habría que añadir en el relato las razones ligadas a la orientación sexual en las que incide el término "sexilio», ampliamente manejado en los estudios LGBT+ actuales (Martínez-San Miguel). La misma narradora ya nos avanza que "No encontré en Borinquen una comunidad gay como la que había dejado en Chicago o la que había presenciado en Nueva York». Probablemente esta imposibilidad de la deportación que conlleva el estatus legal puertorriqueño sea uno de los motivos por los que el/la protagonista de este relato se permite la observación y experimentación urbana: «Siempre que podía iba al Broadway Limited (el bar-disco de la época), en las calles Broadway y Belmont. [...] Al principio era un gran voyeur y flâneur». Este tópico del flâneur gay ha sido explorado ya por algunxs autorxs que estudian la individualidad gay urbana como en los trabajos de Ivanchikova y Glaizar, y cobra, además, especial relevancia en los contextos migratorios hispanos como, entre otros, en el caso del protagonista de la novela El jinete azul, del mexicano José Rafael Calva.

Encontramos asimismo un nuevo punto de interés en cómo el relato detalla la compleja relación de las comunidades LGBT+ con los discursos científicos de la época, si bien habían comenzado el que sería un largo camino hasta la despatologización -la Organización Mundial de la Salud dejó de considerar enfermedad la homosexualidad en 1990 y la transexualidad en 2018- lo cual muestra el conservadurismo de las clases médicas. El texto refleja estas tensiones tanto en el relato de diferentes protestas como en las consideraciones personales de los personajes: "Cuando le conocí no tenía ningún problema en aceptar su identidad, llamada para aquella época por los analistas como "homosexual" -no nos gustaba el término, que es de índole patológica y enfermiza». También en relación con esta tensión entre las sexualidades disidentes y los discursos médicos, Luis Felipe / Lizza Fernanda describe las intervenciones quirúrgicas de quienes considera las primeras «transgéneros» hispanas: «Para esa época del '76 había dos o tres chic@s en el área que habían intervenido sus cuerpos, agrandándose las nalgas y los senos, siendo los primeros transgéneros latinos de los años 70». Igualmente denuncia que estas mismas mujeres acababan recurriendo a manipulaciones u operaciones clandestinas debido a las dificultades económicas que imponían los cirujanos locales con las nefastas consecuencias que podían acarrear: "Creo que el silicone que se inyectaban otras, procedente de Méjico, no era aplicado por profesionales sino por ellas mismas o por gente nada profesional. Obtener un médico que supiese de cuestiones de transexuales era algo complicado y caro"?.

Estas son tan solo algunas de las cuestiones por las que transita el texto, que merecerá análisis más detallados en el futuro. No obstante, preferimos que sean lxs

7 Pueden establecerse paralelismos con las vivencias de Mejía a propósito del contexto espanól o de Sosa Villada sobre el argentino, por ejemplo. 
lectorxs e investigadorxs que acudan a él quienes puedan enriquecerse con este insólito testimonio. Deseamos, en cualquier caso, que esta edición resulte estimulante y que confirme el interés de la recuperación de estos «relatos de vida», pues estos testimonios ofrecen relatos de las muy diversas maneras que existen -y han existidode negociar identidades, géneros y sexualidades. Agradecemos muy sinceramente el permiso de Luis Felipe Díaz / Lizza Fernanda a publicarlo en este monográfico. Y, por supuesto, su entrañable cariño y su tan vital generosidad. 


\section{BIBLIOGRAFÍA}

Berzosa, Alberto; Platero, Lucas; SuÁrez, Juan Antonio y Trujillo, Gracia (eds.). Reimaginar la disidencia sexual en la España de los 70. Redes, vidas, archivos. Barcelona: Bellaterra, 2019.

Berzosa, Alberto y Trujillo, Gracia (ed.). Fiestas, memorias y archivos. Politica sexual disidente y resistencias cotidianas en España en los años setenta. Madrid: Brumaria, 2019.

Calva, José Rafael. El jinete azul. Ciudad de México: Katún, 1985.

Díaz, Luis Felipe. Ironía e ideología en La Regenta de Leopoldo Alas Clarin. Nueva York: Peter Lang, 1992.

Díaz, Luis Felipe. Semiótica, psicoanálisis y postmodernidad. Guaynabo: Plaza Mayor, 1999.

DíAz, Luis Felipe. La na(rra)ción en la literatura puertorriqueña. San Juan: Huracán, 2008.

Díaz, Luis Felipe. Modernidad, postmodernidad y tecnoculturaactual. San Juan: Gaviota, 2011.

Díaz, Luis Felipe. De charcas, espejos, velorios e infantes en la literatura puertorriqueña. San Juan: Isla Negra, 2011.

DíAz, Luis Felipe. Eros y violencia en la literatura hispanoamericana del siglo XX. San Juan: Isla Negra, 2015.

Díaz, Luis Felipe y Zimmerman, Marc (eds.). Globalización, nación, postmodernidad: estudios culturales puertorriqueños. San Juan: Ediciones Lacasa Puerto Rico, 2001.

GlaIzar, José. El flâneur queer en El jinete azul. Tesis de licenciatura. Universidad Nacional Autónoma de México, Ciudad de México, 2017 (http://132.248.9.195/ptd2017/septiembre/0764944/Index.html).

González-Laguer, Joelle (dir.) Luis/Lizza. San Juan: Loka Productions, 2015.

Ivanchikova, Alla. «Sidewalks of Desire: The Invention of Queer Space.» Journal of Contemporary Thought, 33 (2011), pp. 9-28.

La Fountain-Stokes, Lawrence. Queer Ricans: Cultures and Sexualities in the Diaspora. Minneapolis: University of Minnesota, 2009.

La Fountain-Stokes, Lawrence. «Lizza Fernanda (Luis Felipe Díaz)» en Lola Von Miramar, 2013. (http://larrylafountain.blogspot.com/2013/06/lizza-fernanda-luis-felipe-diaz.html).

La Fountain-Stokes, Lawrence. "Mala Mala y la representación transgénero y transformista en el cine puertorriqueño», en Cuesta, Mabel (ed.), Poder, raza y postnacionalismos desde los limites del mapa LGBTQ, San Juan: Isla Negra, 2016, pp. 185-200.

Martínez-San Miguel, Yolanda. “Sexilios”: hacia una nueva poética de la erótica caribeña». América Latina Hoy, 58, 2011, pp. 15-30.

Mejía, Norma. Transgenerismos. Una experiencia transexual desde la perspectiva antropológica. Barcelona: Bellaterra, 2006.

Mérida Jiménez, Rafael M. Transbarcelonas. Cultura, género y sexualidad en la España del siglo XX. Barcelona: Bellaterra, 2016.

Newton, Esther. Mother Camp: Female Impersonators in America. Chicago: University of Chicago, 1972 y 1979.

Perales, Rosalina. «El travestismo como arte: entrevista comentada a Luis Felipe Díaz-Lizza Fernanda». Argus-a, vi, 25 (2017). (http://www.argus-a.com.ar/publicacion/1267-el-travestismo-como-arte-entrevista-comentada-a-luis-felipe-diaz-lizza-fernanda.html). 
Peralta, Jorge Luis (ed.) Antes del orgullo. Recuperando la memoria gay. Barcelona-Madrid: Egales, 2019.

Peralta, Jorge Luis y Mérida Jiménez, Rafael M. (eds.) Memorias, identidades y experiencias trans: (in)visibilidades entre Argentina y España. Buenos Aires: Biblos, 2015.

Ramos-Zayas, Ana Y. National Performances: The Politics of Class, Race, and Space in Puerto Rican Chicago. Chicago: University of Chicago, 2003.

Santini, Antonio y Sickles, Dan (dir.). Mala Mala. Nueva York: Strand, 2014.

Soraya (Bárbara Santiago Solla). Hecha a mano: disforia de género. San Juan: Lúdika Proyecto, 2014.

Sosa Villada, Camila. Las malas. Barcelona: Tusquets, 2020. 


\title{
DEL TRANSFORMISMO TEATRAL \\ A LA PERFORMATIVIDAD TRANSGÉNERO COTIDIANA. FRAGMENTOS DE UNAS MEMORIAS TRANS*
}

\author{
Lizza Fernanda / Luis Felipe Díaz
}

Yo, Lizza Fernanda (Luis Felipe Díaz), como personaje travestido, comencé mi carrera en 1976 en Chicago. Desde Puerto Rico, me había ido a vivir con mi familia a esa bella ciudad en 1965. Sostuve estudios de bachillerato desde 1969 a 1975 en la Universidad de Puerto Rico y al terminar regresé a la Ciudad de los Vientos (Chicago). Para los iniciales tiempos de ese regreso de 1975 comencé a participar en espontáneos shows en las fiestas privadas de los gais, en las playas, en las plazas y frente al Lake Shore Drive. Todo fue inicialmente animado por el deseo de juego y jocosidad, por puro entretenimiento sin pulir, como lo hacían también l@s demás muchach@s que sí se dedicaban al transformismo profesional. Yo, por mi parte, era un muchacho en camino a lo gay, pero bastante masculino e ignorante. Casi todos mis amigos no eran la típica «loca» trans, sino tipos muy masculinos -como son la mayoría de la gente gay, cuando se cree lo contrario-. En la playa, en la orilla del lago que menciono, las llamadas «locas», los domingos por las tardes, realizaban concursos de belleza en los cuales nunca competí porque de día, bajo el sol, vestido de hombre o de mujer, no me veía ni tan siquiera afeminado. El público que presenciaba los espectáculos eran los gais y macharrancitos ${ }^{8}$ de la comunidad latina y negra del área llamada Lincoln Park, al noreste. Ese fue mi barrio desde que tenía más o menos quince ańos. Para esa época fui feliz, a pesar del «saco oscuro» que siempre cargábamos porque notábamos cómo los boricuas no éramos muy queridos en esa ciudad y mucho menos en esa área de blancos. Ser gay «empeoraba» las cosas, pero me las arreglé como pude y le saqué buen partido a las situaciones que se me presentaban y aprendí la «bregadera» de ser gay sin caer en estereotipos. Me encantaba la diversidad de la ciudad, aunque hubiese por allí dos o tres gringos y europeos estúpidos y xenofóbicos. Era la época de la «era disco» (1974-1978) y de la integración etnorracial que pedían las leyes del Estado, y en eso nos amparábamos en parte.

* La presente edición, preparada por Juan Martínez Gil y Rafael M. Mérida Jiménez, forma parte del proyecto de investigación «Memorias de las masculinidades disidentes en España e Hispanoamérica» (PID2019-106083GB-I00), del Ministerio de Ciencia e Innovación del Gobierno de España.

${ }^{8}$ Voz puertorriqueña para designar un hombre de aspecto muy masculino y performatividad heterosexual (en general, se trata de bisexuales) que merodean en los ambientes festivos gais. A veces son strippers que se dedican a la prostitución. En México se les llama «chacales». No posee connotaciones negativas (n. de los eds.). 
Para esa época del 75-76 había dos o tres chic@s en el área que habían intervenido en sus cuerpos, agrandándose las nalgas y los senos, siendo los primeros transgéneros latinos de los años 70 , junto a otros gringos blancos y negros que desde antes habían realizado lo mismo. Existían ya muchos bares que se especializaban en espectáculos de travestis-transgéneros (las chicas eran sencillamente sensacionales, casi siempre imitadoras o lo que se llamaba female impersonators). Ya tenía fama el gran Baton, un bar-teatro que presentaba los mejores espectáculos de transformistas y en los cuales se podían ver transexuales, los primeros que se habían hecho senos desde los años 60. Yo sabía que desde un poco antes, en Santurce (Puerto Rico), había un club llamado El Cotorrito que podía igualar todo esto, por su calidad tan espectacular, por su secuela de la emigración cubana y de los espectáculos que mediante el cine nos llegaban desde Méjico.

El rechazo no solo venía de los heterosexuales. En el Chicago de la época de la que hablo había oculto prejuicio racial y de género entre nosotros mismos, pero el ser todos gais nos unía de alguna manera muy especial porque notábamos que de esa forma nos iba "más bonito». Yo, en verdad, no tenía una buena idea de qué carajo era todo aquello que estaba pasando. Había estado de los 15 a los 19 años en la escuela secundaria, en Chicago. De lo que antes hablé sobre lo ocurrido en los parques cerca del lago, se relaciona con mis 26 ańos. La gran experiencia bilingüe me había hecho muy distinto e híbrido culturalmente. Y para colmo «de males», estaba en camino a ser gay. «Wao!», me digo hoy día. Sin embargo, no dominaba bien ni el español ni el inglés, me creía que controlaba bien la sexualidad con las mujeres, pero luego me enteré de que no era así. Nunca cuestioné el vestir de varón ni comportarme como tal. Usar ropa de mujer era algo que realizaba de vez en cuando: un relajo, una broma que se tornó cada vez más en algo serio. En la actualidad, cuando escribo esto, no visto de hombre ni poseo ropa de ese género. Mi personalidad y físico han ido variando en gran medida por medio de intervenciones quirúrgicas, rellenos corporales y modificación de conducta. Me considero hoy día un transgénero.

Desde niño, a pesar de que crecí imitando a mis elegantes y siempre bien vestidos tíos, también podía tener gustos muy femeninos -algo que estaba sumergido, no necesariamente reprimido, en mi consciencia- y que aprendí a suprimir debido a la imposición (norma) cultural a la cual fui sometido por la propia familia, y sobre todo en la escuela con mis condiscípulos. Mi madre dice que siempre desde niñito guardaba los zapatos con tacos de mujer que mis tías desechaban. Sí recuerdo que siendo muy niño (¿tres años?) encontré un zapato rojo de mediano taco ¡y cuánto hubiese querido encontrar su pareja! Creo que todavía simbólicamente estoy buscando esa otra taca. Siempre pude imitar mujeres (y otros artistas). A principios de los años 60 imitaba con mi propia voz a la gran cantante cubana Olga Guillot y la gente que me escuchaba se asombraba con admiración, pero se asustaba (por mí) a la misma vez: "Este si se cría sale», "Va a ser pato», "iPero no lo dejen hacer eso!»... Sabía que así calladamente les decían a mis padres. Todo era subconsciente y no significaba que deseara cambiar o abandonar algo de mi ser, sino abonar, añadir, ampliar las maneras múltiples (tridimensionales) de actuar. Pero la gente no entendía, ni comprende todavía, que uno puede salirse de su cauce y seguir otros sende- 
ros sin mayores problemas. Luego te surgen dos caminos, y tres, y cuatro... Hoy día entiendo que estas cosas pueden ser fractales y rizomáticas; es decir, no lineales o binarias ni de causa-efecto.

No realicé imitaciones e interpretaciones para un público gay hasta esa época de mis 26 años. Para ese tiempo solo me interesaba ver los espectáculos y uno que otro nene bonito... y ni tan siquiera de la cuestión de transformista estaba tan seguro (ya casi no salía con chicas, como antes). Poco a poco las fui abandonando y los muchachos me fueron gustando mucho más. La vida gay del transformismo y travestismo representaba algo mínimo en mi vida en torno a 1975-76, pues era mucho lo que tenía que estudiar ya que iba tras una maestría en Spanish, Italian and Portuguese, con concentración en Lingüística Aplicada y un poco de Estudios Latinoamericanos en la Universidad de Illinois (campus de Chicago). Junto a los estudios me dedicaba a trabajar, trabajar, trabajar, dando clases en cuanto colegio había en la ciudad para poder sobrevivir modestamente en una urbe tan cara, y viviendo solo, pues me habían botado de mi casa desde los 13 ańos y aprendí a sobrevivir donde fuera. $Y$ tuve que trabajar para pagar apartamento, muebles, trastos, abrigos y los muchos tragos que me bebía y los cigarrillos que me fumaba. Me empezaba a ver (en mi imaginario) como si fuera Bette Davis o María Félix. El Marlon Brando y el Clark Gable, que me imaginaba desde niño, pasaban cada vez más a un plano secundario. Nunca tuve problemas con verme varonil, como ahora no tengo conflictos en verme como una señora. Los analistas tienden a ser muy freudianos y en lo primero que piensan es en el trauma. Para muchas de nosotras esos procesos se dan de manera fluida desde el preconsciente y desde la tecnología biológica de nuestros cuerpos. Pero no niego que siempre surja algo de asombro y sorpresa ante todos estos cambios tan drásticos.

Como dije, me fui a estudiar a la Universidad de Puerto Rico entre 1969 y 1975. Cuando regresé a Chicago en 1975 comencé poco a poco a hacer vida de joven gay. Siempre que tenía la oportunidad, iba al Broadway Limited (el bar-disco de la época), en las calles Broadway y Belmont, un área al norte, cerca del lago y que estaba poblada mayormente por blancos gringos. Comencé a tener varias amistades del ambiente gay que no tenían nada que ver con la academia y que a mi simple e ingenuo entender vivían ese tipo de vida nocturna todo el tiempo. Eran muy dados a las drogas y a la bebedera y por supuesto a la chingadera, como decían los mejicanos. Yo siempre fui más tranquilito en cuestiones de sexo; creo que sublimaba mucho en los estudios. Al principio era un gran voyeur y flâneur. Más adelante aprendí otras cosas diferentes y transgresoras, pero siempre me defendí mucho de las drogas que provenían de la era de los jipis, de mediados de la década del 60. Los conocía y entendía muy bien y, en mentalidad, era como ellos, aunque no usase sus vestimentas ni consumiera sus sustancias especiales; ya sabía de Herbert Marcuse y uno de mis mejores amigos era muy dado a las drogas fuertes. Muchos de ellos estaban políticamente organizados y me motivaron a seguir a Angela Davis, la líder comunista negra de aquella época. Desde joven era independentista en las cuestiones ideológicas de Puerto Rico, pero no era comunista a pesar de que me agradaba el marxismo y el trotskismo. Notaba que los integrantes de la izquierda dura eran muy machistas y homofóbicos. 
Era también época de ir a los cines, a los bar-restaurantes por las noches, bien tarde, a comer hamburgers y hotdogs, batidas de fresa o vainilla; de ir a obras de teatro vanguardista, ver los ballets rusos que venían a los mejores teatros de Downtown y de besar chicas y más, poco a poco, a los chicos. De ver (ligar) más de reojo a los muchachos guapos y de suculentos cuerpos y asistir a los lugares más apartados y semioscuros a ver cosas diferentes, como los demás gais y sus diferentes maneras de ser. Yo esperaba, en competencia preconsciente con los demás, que me mirasen más a mí y me hicieran más fácil la rápida conquista "amorosa», pues me decían y repetían que era muy bien parecido y yo me lo creía. En general, me iba bien en el sexo rápido y anónimo, pero muy mal en el amor.

Nunca coqueteaba, ni menos me acostaba, con amigos sino con desconocidos que nunca volvería a ver. Los amigos eran quienes me animaban a travestirme para participar en las paradas gais, en «el día de las brujas» principalmente (que comenzó a ser un gran acontecimiento entre los gais de ese tiempo). Se corrió la voz entre ellos de que yo tenía algo así como una doble personalidad: podía ser muy masculino cuando vestía comúnmente de varón y mientras estaba travestido parecía una artista del cine mejicano. También eran ellos los que me llevaban a participar en los espectáculos improvisados en los sótanos de las casas y en los bares clandestinos y sin licencia de la ciudad. El alcohol y las drogas eran el toque festivo, además de la «música disco». Fueron varias las veces que nos sorprendió la policía. A mí y a mis amigos cercanos, que eran en su mayoría boricuas, nunca nos arrestaron, principalmente porque no éramos emigrantes ilegales y sabíamos comportarnos ("calladitos se ven más bonitos», como los oficiales lo pedían), además de que sabíamos inglés. Las «locas» («jotas») $)^{9}$ extranjeras se ponían bien bravas y atrevidas con la policía. Tampoco cabíamos en la perrera, que casi siempre estaba atestada de mejicanos «ilegales». Muchas locas mejicanas fueron arrestadas y llevadas por los policías de la migra ${ }^{10}$ a lugares muy lejanos (más allá de la frontera) y nunca más las volvimos a ver. Los boricuas sufríamos muchas veces por esas personas, cuando ellos creían que nos burlábamos. A veces no había tan buena química entre los mejicanos y nosotros, pero poco a poco las cosas fueron cambiando y nos entendíamos cada vez más. A mí me querían mucho de Luisa (así me llamaban en ese entonces) porque con los ojos y los labios bien delineados y pintados me parecía a las artistas mejicanas clásicas de los años 50. Y era verdad, porque aprendí a pintarme la cara mirando en la tele y el cine a aquellas artistas como María Félix, Silvia Pinal, Elsa Aguirre, Dolores del Río y Olga Guillot (que era cubana). En Puerto Rico me fijaba bien en Marta Romero, Lucy Fabery, Martita Martínez, Esther Sandoval, Beba Franco, Marisol Malaret, Carmita Jiménez, Ivonne Coll. Iris Chacón vino después y, aunque la admiraba, no me animaba a imitarla en nada, no sé por qué razón. ¡Todas las locas

9 "Joto» es uno de los términos utilizados en México y Honduras para designar despectivamente a una persona homosexual $(D L E)$. Actualmente los gais se han apoderado del término y lo emplean sin las connotaciones negativas que suele tener (n. de los eds.).

10 «Migra» es el término que emplean las comunidades hispanas migrantes para hacer referencia a la policía migratoria de los EUA (Diccionario de americanismos) (n. de los eds.) 
querían parecerse a la gran Iris Chacón! ¡Y cómo no fijarse en aquellas divas, como Sara Montiel, Lola Flores, Marisol, Rocío Dúrcal o Rocío Jurado!

Tenía en Chicago, para aquella época de mediados de los años 70 , un amante llamado Pat, quien era un verdadero queer y crossdresser. Le gustaba comprar piezas femeninas, por el puro placer de tenerlas en su armario; especialmente bufandas, lápices de labios, pañuelos, tacos, estolas. Le agradaba tener en la casa, y las usaba, prendas de ropa interior de mujer, sobre todo satinadas y con encajes que no sabría describir, pero que eran muy femeninas y elaboradas. También acumulaba maquillajes y perfumes que no usaba porque prefería emplear los que tenía para hombres -creo que eran marca Aramis-. Pero nunca se vestía de mujer por completo. Era un fetiche que poseía con ciertas prendas y por el placer de tenerlas y a veces usarlas en la casa. Mi interés en estas piezas era distinto, pues sabía usarlas en la calle sin ninguna vergüenza o temor. Y a él le impresionaba mi situación porque yo era el «machito» de la relación (sería el bigote y medio que yo llevaba casi siempre, como Jorge Negrete). De todas maneras, cuando vestía de mujer para asistir a los clubes, él me ayudaba a arreglarme lo mejor que podía, pues insistía en verme como una dama seria y no tan cómico y payasote como los demás travestis. En mi caso, el vestir de mujer no era nada privado sino público, para espectáculos, contrariamente a muchos otros que lo hacían por cuestiones secretísimas y sexuales.

Pat había sido un niño de Wisconsin (de madre australiana y padre suizo), muy feliz en su infancia (contrariamente a mí) y que ya a los doce años sabía lo que significaba ser marica, pues desde joven sostenía relaciones sexuales con sus hermanos, primos y vecinos, y con medio mundo. Cuando lo conocí no tenía ningún problema en aceptar su identidad, llamada para aquella época por los analistas como "homosexual» -no nos gustaba el término, que es de índole patológica y enfermiza-. Pat tenía la identidad gay bastante definida y no rechazaba su "femineidad» (era bastante amujerado y fino, como andrógino), a la vez que disfrutaba de la sexualidad gay que la naturaleza le había asignado (así lo veía él, quien no era en nada religioso y a pesar de su pasado con padres judíos, que sospecho no eran tan estrictos en estas cuestiones). Lo único que le molestaba era que oliese a mujer en la cama, con aquellos perfumes tan "penetrantes» que yo escogía. Desde entonces me baño y me limpio bien antes de ir a la cama, aunque esté solo, como hoy día, en 2020. ¡Cómo pasa el jodido tiempo! ¡Y los perfumes cambian también! He coleccionado hasta cuarenta o cincuenta frascos de perfume de mujer. ¡Algunos otros gais nada afeminados almacenan muchos más!

La mujer cómica que los travestidos crossdressers buscaban en su interior (no debo incluir en esto a Pat, creo) era una chica muy ridícula que veían adentro de sí, como medida de rechazo risible a sí mismos y para demostrarse que no eran mujeres a pesar de que les gustaban los hombres. Se confundían porque como varones les gustaban otros hombres y creían que eso los hacía amujerados en lo sexual; hoy sabemos que no resulta así. Una cosa es que te gusten los hombres como cuestión sexual y otra que quieras verte como mujer. El que te guste lo femenino no te hace nunca una mujer biológica. Ser afeminado puede resultar una faceta más de ser masculino u hombre - que yo he buscado y alcanzado, por cierto-. Son las diversas maneras en que los hombres gais asumimos lo femenino. Por otra parte, much@s 
transexuales que ni siquiera tienen un pipi ${ }^{11} \mathrm{o}$ algo parecido, como señal del sexo que les dio en un principio la naturaleza, sí se consideran mujeres (y eso no se debe cuestionar, pues ellas se entienden; es bueno preguntar cómo desean ser interpeladas). Yo no era ni soy así. Más bien en aquella época entendía que quería verme como mujer porque algo interno y psíquico me lo pedía, pero no tenía duda de que seguía siendo un hombre, un varón natural (con un pipi), que me gustaba tener otro hombre en la cama pese a que me gustaba vestir y conducirme como una mujer en público. ¡Eso era distinto a ser como una mujer o el típico trans!

Esa era una de las muchas maneras que hay de ser gay. Y me libré de ansiedades innecesarias, contrario a algunos de mis amigos que se aterrorizaban con la idea de que los vieran como mujeres, cuando algunos eran en verdad muy afeminados. Su travestismo era un proceder ensayístico e iniciático por el que pasan algunos gais en la comunidad nuestra. Luego abandonan el travestismo y siguen siendo hombres que se acuestan con hombres, independientemente de su imaginario de género, véanse masculinos o más femeninos. Por eso la mayoría de los gais no tienen nada que ver con ser amujerado, travesti o incluso afeminado, como suele creer en general el público que no sabe mucho de estas cosas. Creo que incluso nosotros mismos tenemos problemas entendiéndonos. Estamos obligados a usar un lenguaje androheterodesignador que no concuerda con lo que queremos ser y decir. Ese lenguaje simbólico, personal y cultural, que nos defina mejor lo estamos creando ahora, parecido a lo que las mujeres comenzaron a realizar desde principios del siglo xx. La mujer se sigue redefiniendo y construyendo en su propio lenguaje y símbolos, lo que la define en su diversidad otreica y diferenciada en nuestros tiempos. Los hombres heterosexuales tendrán que cambiar también su manera de definirse porque el mundo se ha transformado y ellos no. jY su performance de machos les está quedando cada vez más feo y passe!

Se tenía un pobre concepto, primero de lo que era ser gay y luego de lo que era ser un travestido (así lo entiendo hoy). Pero esa no era mi sicología, era diferente de lo que era distinto (¡qué lío!). Primeramente, yo anhelaba hacer algo artístico y elegante y había dentro de mí una energía subliminal que los mismos gais masculinos amigos míos no tenían. La energía esa la poseían las llamadas «locas», así que yo sospechaba que era más como ellas y no como mis macharranes amigos, ni incluso como yo mismo, que vendría a ser como mis tíos: masculino en mi proceder social y corporal, más varonil que incluso mis amigos de juerga. Me identificaba espejísticamente (en lo preconsciente) con mujeres parecidas a las que veía en las películas mejicanas y de los Estados Unidos de los años 50 y 60. Muchos de mis amigos no sabían ni quiénes eran Jean Harlow o Kim Novak ni se habían fijado tan bien en los peculiares rostros de ellas, como yo lo hacía desde muy niño. Sabían de la Lupe, Iris Chacón y sus locuras y extravagancias rápidas, los relajos y gufeos ("cachondeos», dicen los españoles). Casi todo de fiesta y carnaval.

11 Forma informal para "pene» en algunos contextos latinoamericanos. También es una forma popular en registros cultos espontáneos (Diccionario de americanismos) (n. de los eds.). 
Yo tenía otros pensamientos y otros modelos. No era el típico boricua del Barrio y sus gustos salseros y pachangueros (unas pocas veces, sí). Era un jíbaro de Aguas Buenas, Puerto Rico, que se había modernizado de una manera muy peculiar -aburguesada, creo- en Chicago, con una diversidad muy amplia de gente, ya locas o heterosexuales. Nunca me sentí ser del Barrio, sino un emigrante metido en un mundo de gringos, negros y otros emigrantes europeos. Mi imaginario era distinto al del típico boricua. Mi familia siempre vivió en el norte de Chicago, entre una gran diversidad de gringos mayormente blancos, trabajadores diestros en aquellas fábricas tan extrañas de la ciudad. La mayoría de los puertorriqueños, por su parte, vivían mayormente en el centro de la ciudad, en las calles Division y California. Yo tenía que viajar a los lugares diversos a ver las películas hispanas y de los artistas que nos visitaban desde Méjico y Puerto Rico. Veía mucho a los artistas mejicanos, sobre todo, quienes producían buenas películas y poseían buenos teatros y salones en la ciudad. Muchos mejicanos en ese entonces vivían al sur de la ciudad. Mi familia, sin embargo, quería americanizarse, no sé por qué razón, y yo me veía como un emigrante en aquel país en que siempre sería extranjero y yo no aspiraba a cambiar para ser aceptado. Mis familiares sí, como muchos hispanos. En realidad, pensaba: « $\mathrm{Al}$ carajo con gringolandia blanca y racista, aunque viviera allí en una tierra que ellos habían invadido matando cuanto indio encontraron en su camino!». Aquella tierra forrada de hierro y cemento era tan nuestra como de ellos. Quizá por ello mantuve mi identidad de transgénero de tipo latino, incluso cuando doblaba números gringos, como los de Liza Minnelli y Patti LaBelle. Repito: no me gustaba imitar. Quizá porque estaba construyendo mi propia identidad, la que tengo hoy en el diario vivir, como Lizza Fernanda. Más bien doblaba las canciones y les daba mi propia interpretación escénica.

En una fiesta que realizó mi amigo-amante Pat en una ocasión (la loca era exquisita para estas cosas), todos teníamos que imitar a alguna artista y la mayoría lo tenían que hacer bien travestidos. Alquilaron profesionales maquillistas y peluqueros para el evento. Se divertían muchísimo y terminaron haciendo, en verdad, las parodias más ridículas que se podían ver, porque eso era lo que deseaban y lo que se esperaba. Todo era para morirse de la risa y la diversión era tremenda. ¡Nunca me reí y gocé tanto! Al tocarme el turno, todos hicieron silencio y se pusieron serios porque sabían que iba a doblar y bailar con seriedad dos canciones de Lissette: «Copacabana» $\mathrm{y}$ "Ni su hombre ni su amante». Pat entendía mucho de cómo yo era y de mis gustos, y me había confeccionado una trusa con un plumero rojo muy elegante y vistoso. Los zapatos eran muy altos para mí y me costó trabajo moverme con ellos en el improvisado escenario (la loca los compró como si fueran para ella, pues era muy diestra empleándolos). Pero creo que a mí fue a la única persona que aplaudieron con seriedad y me dieron dinero (nos metían billetes en el seno), porque la verdad era que los demás estaban en la joda y se veían y actuaban lo peor posible. Casi todos estaban borrachos o endrogados hasta el culo. Con sus performances «tan mal realizados» quizá se dejaban saber a sí mismos que no eran gais afeminados cuando la mayoría en verdad lo era. Algunos sabíamos que en inglés simplemente eso se llama denial (negación subconsciente de sí mismo). Pero así sobrevivíamos, y ya todos sabíamos que estábamos sumergidos y jodidos en una sociedad que no 
nos quería ni nos entendía. Creo que nosotros como gais, a mediados de los años 70, no nos entendíamos mucho tampoco. Tuvimos que aprender de nuestra diferenciada sexualidad, primero, y luego de la experiencia del sida, a principios de los años 80. Entendimos que el cuerpo además de estar estrechamente ligado al espontáneo placer también lo estaba con la muerte. La alegría y el carnaval se nos convirtió en luto y llanto.

Un joven que estaba allí en la fiesta me invitó, más adelante, a realizar los mismos números musicales en un club de la ciudad en el cual celebrarían su cumpleaños. La maestra de ceremonia sería Mrs. Kitty, la famosa transgénero, a quien yo no había oído mencionar nunca. Ya en el espectáculo, al cual acudió mucha gente, me mostraba muy nervioso, pero quería llevar a cabo aquella hazaña a como diera lugar, frente a tanto público eufórico. De niño siempre quise ser cantante y que me aplaudieran, pero no tenía voz. También era muy nervioso de varón, pero descubrí que vestido de mujer no tanto. Aquella era una gran oportunidad para mi narcisismo en aquella tremenda discoteca con artistas tan profesionales de ese ambiente travesti y un público de locas muy exigente. Me sentí muy extraño en el camerino rodeado de tantas artistas travestis y transexuados muy diestros en todo, y que me miraban con disimulo, y envidia, porque tenía buena piel y buen cuerpo pese a ser varonil. Mi vestuario era el más vistoso y mi cuerpo, aunque masculino y fibroso, de bailarín, era muy limpio y terso, como el de las mujeres. Al final, muchos de los que me conocían no podían creer que lo hiciese mejor que varias de las otras artistas que estaban allí actuando. De ahí en adelante, Mrs. Kitty me invitaría a salir en sus shows en el Club Normandie y mucho más cuando me pagaba lo que le daba la gana (casi nada), aunque siempre me dejaba beber de gratis durante toda la gestión artística y mientras ella estuviera en el bar. En ese entonces yo ingería bastante alcohol y fumaba como Bette Davis. Muchas de las transexuales serias no tomaban alcohol ni fumaban porque sabían que arriesgaban el tratamiento de hormonas y el silicone barato de Méjico que se metían en las nalgas y en los senos. No obstante, ¡curiosamente ingerían otras cosas más peligrosas a la larga! Nunca me enteré de qué carajo era lo que se metían en el cuerpo, y me alegro de ello, porque nunca desarrollé vicios a las drogas y a otras sustancias, tan dañinas. Mi vicio era leer en ese mundo donde casi nadie estudiaba; decían que el Quijote era el segundo libro más leído, después de la Biblia. En realidad, no habían leído ninguno de los dos.

Para principios de los años 80 , soy llamada a trabajar en algunas ocasiones como «bateadora emergente» (sustituyendo las que se ausentaban a última hora) en discotecas y salones de cierta importancia - pero para de vez en cuando, porque tampoco era cuestión de todos los fines de semana-. Ya el público no me veía como una travestida más. Esos bares eran Broadway Limited, El Infierno, La Cueva, Normandy, que no eran los clubes escondidos y clandestinos de la comunidad latina, como antes. Mrs. Kitty -quien era más bien una transgénero con senos siliconados, hechos en Méjico, pero creo que mantenía un pequeñísimo pene bien escondidodominaba totalmente el ambiente de los travestis en Chicago. Seguía invitándome constantemente a sus espectáculos, que por lo regular eran en renombrados clubes gais de la ciudad (dentro de lo posible, porque en verdad, a veces eran salones que no estaban del todo bien arreglados). Y actuaba con las mejores artistas, en su mayoría 
transgéneros con unos senos, pómulos y labios enormes y exagerados. Todas decían que era mucho el dinero que Kitty ganaba y poco el que repartía (era como una Celestina bella, parecida a Sara Montiel). Salía al escenario con los trajes más impresionantes, de canutillos, confeccionados en Méjico. No doblaba bien las canciones, pues no sabía respirar como cantante, pero se las arreglaba con habilidad para verse bien. Tenía un cuerpo que pocas mujeres poseían y su rostro estaba maquillado como el de una diva de cine. Antes de yo conocerla -me dijeron- podía bailar casi desnuda (como las chicas de los burlescos), pero con buen gusto, nada vulgar. Su rostro se veía muy bien en el escenario, pues no tenía mucha mancha de la barba.

Una que otra vez, me dijo dos o tres cositas algo insultantes (como hacía con las demás, a quienes veía como inferiores) y yo le respondía con las miradas del mismísimo infierno, sin hablar siquiera, pues había visto bien cómo lo realizaba María Félix. No obstante, Kitty era buena persona, una empresaria muy exitosa, y todos la respetaban. A mí me tenía una consideración y un cariño muy especial. Para ella curiosamente yo era un «hombre» y no una loca como ellas. ¡Decía que yo era un hombre talentoso! Por eso muchas de las travestis más chismosas y envidiosas se extrańaban de que yo estuviera casi siempre presente en esos shows importantes, pues consideraban que yo no estaba al nivel de ellas. A menudo se reían de mí cuando me veían vestido de hombre. No obstante, comenzaba a tener seguidores, y sobre todo la pandilla, que casi siempre me acompañaba e iba a verme, eran mis primeros fans y gastaban bastante dinero en el club, lo cual agradaba a los dueños. También les gustaba mi música doblada, la cual era más retante, compleja, difícil en su sonoridad y de nostalgia casi legendaria. Eran las canciones de madres, tías y abuelas nuestras: «Amor perdido», «Perfidia», «Acompáñame», «Boca rosa», «Un poco más», «Tú me acostumbraste», «Me importas tú», «Bésame mucho». Todavía las doblo (lip-sync, como decían en inglés).

Por mi parte, no sabía separar bien mi masculinidad de mi femineidad y no dejaba de ser lo que llamaban los gringos, con sentido despectivo, un crossdresser; las otras trans me lo dejaban saber constantemente con burla y deseo de ayudarme a la vez. Me decían qué estaba realizando, qué no se veía femenino y cómo mejorar. Para mediados de los años 80 alcancé mayor dominio del escenario y logré aparecer en espectáculos junto a travestis y transexuales cada vez más profesionales y talentosos que me sirvieron de guía, pues les robaba los trucos, observando y copiándolo todo. Nunca estudié peluquería, ni maquillaje, ni modelaje, ni nada por el estilo. Sí estudié algo de baile. Era simple talento -más atrevimiento que nada- de una "loca». El lugar que me faltaba alcanzar en performance era Le Baton Lounge, donde nunca me invitaron ( $y$ creo que en aquel tiempo no tenía la experiencia ni el porte para salir al lado de aquellas «mujeres» tan fabulosas, como Chili Pepper y René Dejené). Me ha costado algo de trabajo llevar el cuerpo masculino que siempre he tenido al imaginario de mi consciencia que se concibe dentro de lo femenino. Llevar el cuerpo al aspecto aparencial que la consciencia quiere poseer exige un trabajo enorme. Primeramente, se requiere creer que se ha logrado ese acercamiento para comenzar a convencer al público de que puedes ejercer el simulacro de ser una mujer, luego de saber una gran cantidad de trucos que requieren manejos de ilusión óptica y teatral. Si te crees que te ves y actúas como una mujer artista y el público no lo ve así, haces 
el ridículo. Y mucho más difícil es verte como una mujer continuamente en la vida diaria, hasta que se olvida que eres/eras, biológicamente, un hombre.

Muchas de las chicas de Mrs. Kitty poseían cuerpos muy afeminados y tal parece que la cuestión del proceso no les resultaba tan difícil como a los que éramos más varoniles. Sin embargo, la mayoría de ellas permanecían escondidas de día y solo salían de noche por más femeninas que se viesen. Creo que tenían paranoia y hasta terror de que de día en la calle se dieran cuenta de que eran, en verdad, hombres. A la misma Kitty se le notaban algunos pelitos de la barba y del pecho, bajo la luz del día. A veces su caminar en la calle resultaba algo varonil. ¡No tomaba alcohol porque es en ese estado de embriaguez que a las más trans se les sale el macho! Pero todavía hoy día no he visto una trans como ella, tan dedicada y profesional, trabajadora, buena gente en el fondo, empresaria, bella. Doblaba las canciones muy mal, pero modelaba y bailaba muy bien, y sus trajes, como dije, eran hermosos, hechos en Méjico y Colombia. En las entrevistas decía que siempre fue la otra, ningún hombre fue suyo.

Por mi parte, observaba y copiaba todo lo que ellas hacían con sus maquillajes y trucos para arreglarse el cuerpo (las caderas, los senos, las nalgas, la cintura, el pelo). Pero en mi proceder corporal y coreográfico en el escenario, sin embargo, no miraba ni seguía a nadie, pues ya desde niño tenía una idea de cómo actuaba una diva cantante en las tablas, frente al público, y eso era lo que yo quería proyectar. No me interesaba imitar a nadie, ni a la propia Liza Minnelli (con quien me comparaban tanto). Mi estilo era más estilizado y elegante que el de la mayoría de las que conmigo trabajaban y, sobre todo, podía doblar mejor, según me decía la gente del público. Las canciones de ellas eran animadas y jocosas, especialmente las de las mejicanas. Mrs. Kitty me obligaba de vez en cuando a ejecutar uno que otro merengue o una guaracha clásica, pues yo bailaba muy bien. Al público no se le podía presentar tanta balada y boleros cortavenas, pues se aburría. Era gente metida en tragos, que quería diversión, bachata, balloya, relajo, gufeo. Al principio tuve ese tipo de público, luego poco a poco fui ganando gente más sofisticada en sus gustos y reclamos artísticos. En las mesas más cercanas al escenario se encontraba el público más serio, que acudía a ver y aplaudir las travestis más talentosas. Ese era el público en el que yo encontraba apoyo, con sus propinas y aplausos. Me imaginaba que no solo era un aplauso por la actuación en el teatro, sino también en la vida.

La mejor de las chicas travestis y transgénero era Witney Gaytan (una de las querendonas de Mrs. Kitty, que era la mulata más linda y afeminada de todas las chicas de por allí). Para esa época Witney tenía senos muy bonitos, pese a las manchas extrañas en parte de su cuerpo, que ocultaba con maquillaje muy fuerte (Dermablend o algo así). Creo que el silicone que se inyectaban otras trans, procedentes de Méjico, no era aplicado por profesionales sino por ellas mismas o por gente nada profesional. Obtener un médico que supiese de cuestiones de transexuales era algo complicado y costoso. Yo no tenía nada que ver con aquellas cosméticas corporales tan excéntricas. Todavía hoy día resulta muy difícil y delicado convertirse en una verdadera transgénero o una transexual. Pocos médicos están dispuestos a atender la situación (especialmente a los endocrinólogos les aterran las locas y los psiquiatras 
no nos entienden). En Brasil, Méjico, Ecuador, Colombia y Venezuela la cuestión era diferente, y para allá viajaban todas las locas que podían pagar. Incluso hoy día es así. Los gringos médicos que atienden locas cobran mucho dinero y en Puerto Rico... ni se diga. Y por lo general muchos de estos médicos son homófobos o no saben un carajo de nosotras y nuestras identidades.

Yo tenía una idea de cómo sobrevivían con el poco dinero que en verdad les pagaban (pese a las muchas propinas que obtenían), pero no me metía en sus vidas privadas ni las juzgaba. Las drogas pululaban por doquier y muchos de los bugarrones prostitutos terminaban con la mayor parte del dinero en sus bolsillos. En ese ambiente no se podía ser monje ni moralista, había de todo lo que la gente «decente» despreciaba y la «ley» perseguía (como en La Celestina). En verdad no tenía una idea de lo complejo de la marginalidad perversa en el mundo en que me estaba metiendo, pues también había muchos pushers, gansters y gansos de toda índole. Mucho puto astuto. Incluso gente criminal muy peligrosa. Pero mis amigos me vigilaban y cuidaban porque algunos de ellos sí se las sabían todas y dominaban aquel ambiente (especialmente mis queridos amigos Jorge y Carlos, quienes ya murieron a consecuencia del sida). Y así sobrevivían... y yo al margen de muchas cosas, solo pendiente de mi imagen como travesti y artista, y más atento a mis estudios de lengua y literatura. En verdad dependía económicamente de otro mundo, el académico. Me movía en un mundo de locas y gais que en general no les importaba un "pepino angolo" ni Don Quijote ni La Celestina o Don Juan. ¡Pero yo me divertía con todos aquellos acontecimientos y era un tanto feliz!

Había presenciado en Chicago las protestas de los negros, cuando el asesinato de Martin Luther King y el del joven Kennedy, y los levantamientos boricuas en contra del racismo y la mala fe de convivencia social, ocurridos en Humboldt Park a fines de los años 60 y principios de los 70. Los boricuas, al igual que los negros, luchaban por encontrar lugares donde vivir y muchas veces se abrían paso a palo limpio. Uno que otro sacaba el puñal y la dońita, el caldero prieto para achocar a uno que otro guardia o polaco racista (;42nd Street!). Para esta época también había surgido una comunidad gay muy visible en algunas partes de aquella ciudad ventosa, sobre todo en las calles antes mencionadas, cerca del lago Michigan. Pero a mi entender, en la ciudad, a la orilla del lago, no había ocurrido nada parecido al sonado evento del 69 en el Stonewall del Village de Manhattan, Nueva York. Allí los gais caminaban por las calles más abierta y libremente. Creo que en Chicago no lo hacían tan sueltamente (aunque no tan a ocultas y con algo de temor como ya vería luego que ocurría en Puerto Rico).

Para mediados de los años 70, siendo residente en Chicago, me había enterado de la militancia política y cultural de los queers (que también se daba en las principales ciudades del país). Ello se evidenciaba por la distribución - principalmente en las paradas en junio y en los propios bares y discos- de desafiantes periódicos, revistas y pasquines de todas clases. De fácil obtención eran las propagandas con todo tipo de información, desde dónde conseguir un abogado gay hasta el número telefónico de una tienda de zapatos de mujer, con tamaños superiores al número 15 (idóneos para crossdressers y dragas en sus fiestas de Halloween). Pero en verdad, pese a toda esta propaganda y literatura, entendía que la mayoría de los gais se mostraban más 
interesados en el hedonismo y el performance discotequeros que en la relevancia de la militante prensa informativa. Una cosa iba con la otra porque eran las discotecas más adineradas las que pagaban los anuncios comerciales de estas revistas y las actividades de los grupos y les daban movilidad. No tan cercano a estas cuestiones había estado yo en mi vida de gay y no conocía tanto la militancia civil y política, como muchos otros, que ya era muy avanzada y compleja. No obstante, el grupo de gais y lésbicas al frente de todo era más que suficiente para ofrecerle sustancia militante e ideológica al movimiento. Chicago también sería una muestra de lo que ocurría en la emergente subcultura gay para fines de los ańos 60 e inicios de los 70 en muchas partes del mundo.

En Puerto Rico, para esa época, había mucho chingoteo gay y creo que muy poco de militancia política o cívica. Esto vendría mucho después, ya siendo yo profesor universitario en los años 90. Para el año 1988 un profesor gay de mi universidad, muy chingón pero closetero (todavía en el 2012), insistiría que en Puerto Rico no había una comunidad gay. Creo que estaba equivocado, pues la había, aunque mínimamente. Sobre todo, lo convocaba la problemática médica y social del sida. Ese profesor nunca ha aceptado ni dicho que fue paciente de tal síndrome. Sigue vivo y muy saludable y ha sido una persona muy valiosa en su comunidad. El estar enajenado de la propia identidad gay no quita el ser una persona digna en tu comunidad. Pero a esas alturas ya los gais en general no veían nada bien a los que se mantenían en el clóset. Creo que fueron muchos los estudiantes y profesores universitarios que, al asistir a mis espectáculos, daban un gesto de salir del armario sexual en que estaban metidos desde nińos. Tal vez esté prejuiciada, pero a los gais latinoamericanos (por cuestiones culturales), creo que se les hace más difícil salir del clóset que a los anglos y a los afroamericanos.

Reconozco ahora cómo la ciudad de Chicago era parte de una gran villa contigua a otras villas quizá más amplias y poderosas (como la de los afroamericanos, los mejicanos, los judíos, los polacos, etc.). Si mirabas desde lo más alto de un edifico (como el Sears Tower) veías muchas pequeñas ciudades dentro de la gran ciudad. En el área más visible y prominente, estaba la megaciudad de los blancos, anglos, yanquis, wasps, europeos "felizmente» asimilados a gringolandia, etc. (como si todos fueran iguales, que justamente no lo eran). Allá, a la orilla del lago Michigan emergía la impetuosa ciudad, dominando, vigilando las demás villas esparcidas a sus pies. Y fuera de identidades étnicas y villanas, los gais actuábamos como una pequeña y nueva aldea cercana al lago. Ya no teníamos por qué escondernos en los parques o en el clóset domiciliario. Y tratábamos de apoderarnos de unas cuantas guaridas (bares, discos, cines, salones) por aquí y por allá, principalmente cerca del lago y en el área conocida como $U_{p}$ Town. Pese a que representábamos a una inaugural subcultura en la vida pública, no dejábamos de exhibir el gesto de nuestras propias culturas, pueblos, etnias, y lo compartíamos, más o menos, con los demás. El nuevo sentimiento de unidad transtribal se evidenciaba mayormente mediante nuestro grupal y continuo danzar al son negrista de Diana Ross y Donna Summer, de Gloria Gaynor y su «I will survive», y Santana (que era más de los ańos 60). La cultura gay y disco nos unía a pesar de nuestras grandes diferencias étnicas, de clase y raciales y de ser parte de una ciudad que nos enseñaba a comportarnos de manera 
racista y segregada. Creo que Chicago siempre fue racista y lo seguirá siendo. La cosa es compleja porque éramos muchas diferencias dentro de una unidad primeramente imaginaria, virtual; alcanzamos un implícito convenio (ser gay) para poder sobrevivir en nuestras «otredades». Si se conocían esos «juegos del lenguaje» no se tendría mayores problemas. Pero era frecuente ver peleas de jóvenes por cuestiones de raza, especialmente entre las locas «hillbillies» (blancas) y los negros del barrio adentro. Los boricuas y los mejicanos nos reuníamos en bares como Mr. Jovanies y The Factory. Había otros bares cuyos nombres no recuerdo porque tenían poca duración; la policía los clausuraba enseguida. Íbamos un sábado y ya el próximo viernes estaba cercado el bar con una cinta amarilla del City Police. «Fuck! A new bar opened... where can it be?», decíamos.

Más allá del goce cancioneril y performativo, algo de mi educación marxista me advertía que de alguna manera actuábamos subrepticiamente manejados por un sistema superior que, pese a su democracia y liberalismo, encerraba un imperialismo astutamente disfrazado. Y aquellos entusiastas angloamericanos gais que nos daban la bienvenida en sus bares y discos, pese a compartir en el bailoteo y en los encuentros eróticos nuestra misma sexualidad (la de los latinos y los afroamericanos), pertenecían a aquella dominante y heterosexista megaciudad que hasta hace poco regía con descaro racista y que vigilaba desde los que eran más que monumentales edificios del Downtown. E El Sears Tower! Desde lugares como ese impresionante centro panóptico provenían las decisiones políticas y económicas, la blanquísima policía y los mensajes de los medios masivos de comunicación que obviamente favorecían la cultura blanca y heterosexual. NBC, CBS, ABC. Esos eran los espacios de los discursos dominantes, a pesar de que en los medios se veía o escuchaba a uno que otro negro o latinoamericano. Había dos o tres estaciones televisivas y radiales latinas donde ni mínimamente se mencionaba el asunto de los gais (las cosas parecen haber cambiado algo hoy día). Recuerdo que un locutor mejicano repetía constantemente, desde la seis de la mañana, en una emisora, y con un acento gracioso: "If you drinking, no driving... and if you smoking... uju papacito: ¡cáncer, cáncer!». A pesar de todo fueron tiempos felices para mí, independientemente de estos eventos tan raros de que estoy hablando. Todavía me veo bailando al son de "Love to Love You Baby», bajo la bola de cristales, y todo el mundo complaciendo (contemplando) mi narcisismo, con sus miradas de admiración. No era el mejor bailarín, pero competía con los mejores. ¡Fumaba y bebía ron Barrilito (rum and coke) como un desquiciado! No sé cómo sigo viva.

Intervención espacial, manipulación comunicativa, vigilancia del Poder Invisible. Me preguntaba si algunos de los nuevos hermanos (las lesbianas y gais blancos), aquellos hijos legítimos del Poder, nos asistirían en comunicar a los padres de la maquinaria, a los programadores del sistema transtribal, que una megaciudad y su cultura pueden ser exitosas y atractivas en la medida en que estén dispuestas a dialogar con las demás tribus y permitir, tolerar y propiciar el derrumbe de las cercas y murallas que nos separaban, para que se cumpla una sintonía y conexión más global, una genuina comunicación. Y también, muchas veces resulta necesario permitir que algunas de esas villas (como la boricua y la mejicana) preserven sus ancestrales y valiosas herencias culturales. Sin embargo, no había ocurrido así con los amerin- 
dios. A la mayoría los habían matado hace tiempo, se habían apoderado de sus tierras y a los que quedaban los emborrachaban en los casinos. ¿Por qué no habría de ser distinto ahora con nosotros? ¿Habríamos de desaparecer? En los inevitables procesos de homogeneidad que teje la historia algunos se desvanecen aniquilados por el impasible Poder y a veces pasan a convertirse en otra cosa y nadie nota nada. Nadie se entera. La historia pasa y las alteridades atroces y genocidas no son narradas. Lo sucedido a los indios frente a Colón, Cortés y Pizarro nos lo demuestra así. Tal vez de alguna manera esas voces silenciadas habrán de aparecer y salir de la tumba del olvido para conocimiento (sufrido) de todos. ¡Los que han sido pacientes de sida y siguen vivos saben de qué hablo!

Curioso resulta que a varios latinos nos sacaba de nuestras villas (fuera del barrio latino) precisamente nuestra identidad sexual y todo era un escape aventurero de aquellos hijos gais de la megaciudad que no podían seguir viviendo con sus hispanos padres heterosexistas. A un latino o a un negro podía prohibírsele la entrada a un establecimiento comercial de blancos heterosexuales, pero en general no a una discoteca o bar gay. Tal vez, sin darnos cuenta, más que a un llamado fraternal acudíamos a la comunidad mariconil o jota, siguiendo la convocatoria de tantos eslóganes comerciales sin genuino interés en raza o género, solo en el semiocapital de que todos podíamos gastar siendo gais, éramos un nuevo público para explotar comercialmente. Resonaban en nuestros oídos "Give me a Bud Light», "Fly the friendly skies of United», "Eastern, las alas del hombre», «Winston tastes good, like a cigarette should». Gais o heterosexuales acudían a esos llamados. Pero, de todas maneras, había un mercadeo con una política diferente que nos convenía y nos interpelaba con nuestros lenguajes mariconiles. ¡Quién sabe cuáles serían las consecuencias de la aceptación del llamado!

Tenía al querido Pat, que me amaba mucho, pero yo no le reciprocaba ese amor (así lo veo hoy día, mas no lo pensaba bien en aquel entonces). En esas cosas yo solía ser muy extraño porque era muy autosuficiente e independiente, y en el amor no se puede ser así. Y llega un momento en que un amante te pide algo más que sexo y salir a las discotecas. ¡A la larga me he quedado solo por ser tan mal amante, en ese sentido! Shame on me! Finalmente dejé a Chicago luego de que tenía algo de control y había aprendido tanto y me sentía a gusto, a pesar de que mi amante me jodía la vida con peticiones amorosas y platónicas que yo no podía entender. "¡El amor es... cuatro letras bien bonitas!», decía entonces y lo repito. Hoy día lo recuerdo con mucho amor y ¡quisiera que estuviera conmigo! Murió en 1994, a consecuencia de otra pandemia, el sida, que hoy día incluso los gais parecen haber olvidado.

Para mediados de los 80 fui a Puerto Rico a trabajar a la Universidad Interamericana, pero siempre que podía regresaba a Chicago (en días feriados, los veranos y las navidades). Mrs. Kitty me recibía con los brazos abiertos, además de mis amigos (muchos de ellos ya con los rostros extraños y cadavéricos, pues los asediaba el sida). No sé por qué en 1983 me fui una vez más de Chicago. Creo que fue un error y ya sigo anclado en esta isla (Puerto Rico) tan adversa para lo que hago como marica. Todavía tenía mucho que aprender: para mí la academia era más importante y el travestismo seguía siendo entretenimiento y juego (al menos eso creía). A todos 
mis amigos de Chicago, cuando iba allá de vacaciones, les encantaba ir a buscarme al aeropuerto, irse de parranda conmigo, y se peleaban por cargar mis maletas llenas con más ropa de mujer que de hombre. Yo volvía a ser feliz allá en Chicago y echaba de menos la ciudad (en Puerto Rico era otra cosa). Cuando podía, en la «ciudad de los vientos", iba también a la librería de la Universidad de Chicago (The Seminary), donde había estudiado por un año, y me fui porque nunca me quisieron algo, pese a que el profesor Ricardo Gullón me defendía muchísimo. Iba a comprar libros de semiótica, de estructuralismo, de Lacan y Foucault, traducidos al inglés, porque en francés eran sencillamente imposibles de entender, no solo por la lengua sino por lo complicado de los conceptos. Las ideas de estos teóricos me ayudaban a entender de las nuevas identidades que a los gais nos interesaba exponer en la sociedad machista y tan heteronormativa en que vivíamos. Peor que hoy día. Hemos ganado territorio. Incluso en Puerto Rico. Hoy leemos a Judith Butler, Luce Irigaray y Julia Kristeva sin problemas.

No encontré en Borinquen una comunidad gay como la que había dejado en Chicago o la que había presenciado en Nueva York. De la mariconilmente concurrida calle Broadway en Chicago o del dinámico Village en Nueva York -con toda la organización subcultural detrás de estos espacios que habían ganado tanto en su lucha por el vivencial y derechos gais- pasaba a un Puerto Rico de maricones tan closeteros e invisibles como jamás pude imaginar. Yo no era particularmente el marica más leído y extrovertido del mundo, pero en gringolandia había ingresado a un proceso de concienciación y destape que, una vez «reinstalado» en la isla, me llevaron los demás a frenar y detener. ¿Qué había pasado con mi proceso? Y ello se manifestaba incluso en las cosas más simples. En Chicago, para emplear un ejemplo superficial de la misma cultura gay de discotecas, cuando me lanzaba a la pista de baile, danzaba como una prima ballerina y hacía gala de mi destreza en ese actuar tan artístico y atlético y nadie me criticaba, jal contrario! Y eso que podía ser modesto en este performance, cuando estaba allá en Chicago, frente al talento de los maricas macharranudos (con sus peludos pechos desnudos y los mahones virilmente apretados) que bailaban lo más pateril y mariconilmente posible en la libre pista, mientras maniobraban majestuosos y amplios abanicos chinos o de plumas de todos colores, como señal de sus nuevas destrezas físicas y de nueva psicología y proeza plumerilmente gay. «iYMCA!» gritaban y danzaban. Entre ellos se destacaban los llamados bears (hombres gorditos, masculinos y peludos). En una discoteca como Bistro cerca del Downtown en Chicago los maricones bailaban y se animaban y había allí una química socioerótica y embriagante que sabía a comunidad nuestra a pesar de todo el racismo escondido y también público en la ciudad. En Puerto Rico me encontré con las discotecas Bachelors y Boccaccio. Eran muy modernas y festivas, pero el público se comportaba de un modo más comedido en cuestiones queer. Nunca en mi vida había presenciado bailarines de salsa tan diestros como los que vi allí. Cuando yo bailaba sentía que me miraban con extrañeza. No entendían cómo un bigotudo tan masculino podía bailar, como una loca desquiciada, música disco. Me sentí muy infeliz y me refugié más con mis alumnos de la academia que sí me aceptaban como profesor. Creo que fui de los primeros profesores (o el primero) que dejó saber abiertamente que era gay y travesti. 
Pese al disimulo y las apariencias, el cruseteo (cruising) era de mayor intensidad que en Chicago y Nueva York, pero peculiarmente disimulado. En el fondo la actividad sexual era la misma; nos sentíamos libres y no veíamos como pecado tener sexo con nuestros iguales. No obstante, en esas otras ciudades el emparejamiento se expresaba de manera más abierta y franca, y hasta descaradamente frívola y sexualizada. En Chicago, una vez alguien me diría: «Would you like to have with me a deep relationship full of meaning for half an hour?». No supe qué contestar a propuesta sexual tan ingeniosa, frívola pero franca. Cosas de locas gringas aguzás y con mucha sapiencia en la gran ciudad. ¡Ahora probablemente están tod@s muertas! ¡Lástima! Yo sobreviví física y mentalmente, pero me he quedado con todos esos fantasmas (como en Pedro Páramo, cuyo protagonista pudo haber sido una loca algo macharrana).

En realidad, pensaba que después de todo regresaría en dos o tres semanas a Chicago, a mis bares Broadway Limited, The Loading Zone, The Factory, The Baton, a las mariconiles calles Clark y Holdsted. Nada más lejos de ese deseo, pues por años he permanecido en la «encantada» isla, desde 1983 hasta hoy día. Ese ha sido mi destino a pesar de que he intentado irme unas cuantas veces. Siempre pasa algo que interrumpe mi regreso a gringolandia. Algún día me iré y moriré por allá y me enterrarán en un solitario y gringo cementerio y padeceré una vez más la muerte de un emigrante abandonado y congelado por el frío, doblemente jodido (emigrante y gay). ¿Quién sabe si me equivoco y he sido agraciado! A veces quisiera que mi entierro fuera en Aguas Buenas o en Comerío, Puerto Rico. Pero ¡qué importa! $\mathrm{Al}$ menos espero que me entierren en alguna parte de este planeta, pues iqué más da dónde carajo te sepulten!

Poco a poco, para fines del siglo xx y de las dos décadas que tenemos encima, además de ser reconocido como un destacado profesor y crítico en la academia puertorriqueña ( $\mathrm{y}$ en Estados Unidos), también me he convertido en la Isla en una especie de Mrs. Kitty. He trabajado como artista en las mejores discotecas y salones gais, así como en algunos teatros y obras dramáticas. Hace ocho o nueve años, se me ocurrió ir vestida de mujer a dar mis clases. Desde entonces no he vuelto a presentarme con vestimentas de hombre en ningún sitio. Todo el mundo me reconoce, y me acepta, como una señora muy distinguida tanto en el performance teatral como en el diario vivir. Como ya dije antes, he realizado ciertas intervenciones quirúrgicas y cosméticas en mi cuerpo, que me hacen una transgénero. En el proceso he aprendido que los trans tenemos que desarrollar una nueva identidad sociocultural y discursiva porque no somos mujeres ni nos sentimos como tal. Seguimos siendo «hombres» gais-transgéneros. Algunos trans sí aspiran a ser como una mujer y emplean todos los recursos médicos y psiquiátricos que tienen al alcance. Ya casi nadie me llama Luis Felipe, sino Lizza Fernanda. Viví un año (2019) cerca de la ciudad de Miami y allí fui acogida por la comunidad de performeros travestis y transgéneros y me fue muy bien como artista (junto a una colombiana travesti llamada Agatha). Mis destrezas y seguridad escénicas me han ayudado a tener gran éxito con todo tipo de público de la comunidad en general. Después, me he trasladado a la ciudad de Nueva York y he podido trabajar como profesora de sociología en el legendario Hostos Community College. Viajo en el tren y mucha gente me mira, pero me han 


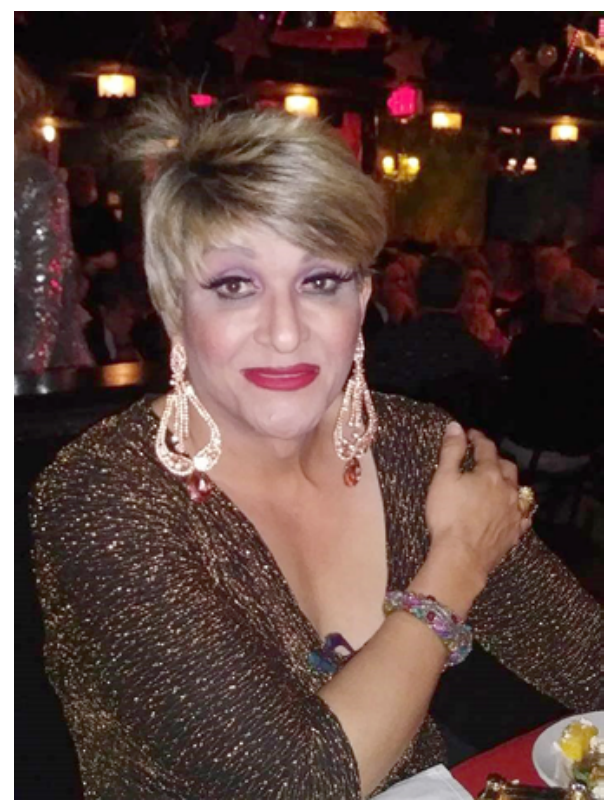

dicho que no es porque se me vea el macho bajo el maquillaje y la vestimenta sino porque parezco una señora muy elegante y teatral. Y así me ven también en el Colegio..., como una señora, diva y legendaria. 
